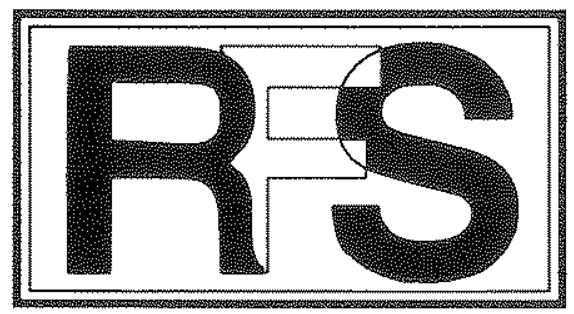

Revista de Fomento Social, 48 (1993), 289-296

\title{
El Magreb ante los desafíos económicos Norte-Sur (1)
}

Desde Marruecos nos llega un análisis sobre los problewas del desarrollo de los paises del Magreb en el mevo contexto internacional Factor esencial del escenario de futuro serán lass relaciones preferenciales con la Com unidad Europea

Driss KHROUZ (*)

\section{Introducción}

Como otros países del Sur, los países del Magreb se caracterizan por su incapacidad para satisfacer las necesidades fundamentales de su población. Esta última es joven y crece mucho más deprisa que la producción de riquezas. Las

(*) Profesor de Ciencias Económicas. Facultad de Derecho Agdal-Rabat.

(1) Traducción de José J. Romero Rodriguez. 
sociedades del Magreb se encuentran achualmente desestructuradas a causa de sus propias mutaciones internas y de las agresiones exteriores. Ellas, también,

La consolidación del capitalizmo en ton otros momentos de su historia. ampliación al norte de Amérilismo en tomo al núcleo europeo y luego su estructuras sociales de estas sociedadesón, ha agravado sus distorsiones. Las raíces, no sonni suficientemente fades seculares tradicionales con profundas capitalista, ni suficientemente fiexibles para impregnarse de la racionalidad periodos donde la dimensión fuertes para generar su propia lógica en unos

ion del capitalismo podía permitirlo.

características esen azones de fondo las economías del Magreb tienen las

en las economías del sur:

- debir atonomía de los sistemas productivos;

- débil reproducción de las riquezas sociales;

- incapacidad para satisfacer las necesidades nados desde el como de los poderes y del saber.

Así el comercio, las finanzas, la ciencia y la tecnología son controlados por el Norte en detrimento del Sur, y ejercen efectos de diferenciación y de asimetria. Son sus víctimas las sociedades del Sur, con la notable excepción en algunos caracteres dominantes- de algunos países llamados semi-
industrializados.

Es bueno reflexionar sobre estos últimos países cuando se habla del Magreb, porque hace unos veinte años, tanto Marruecos como Argelia, poselan sin duda algunos aspectos favorables que han sido mal explotados, mientras que los mismos precedentes han producido cambios en otros lugares orientados al control de los fenómenos económicos a favor del desarrollo.

Los efectos perversos del comercio mundial, del poder financiero y monetario, del saber tecnológico y militar se ejercen así sobre las economias del Magreb. Como todas las demás sociedades del Sur, éstas dependeníntegramente del flujo de riquezas con los países del Norte. Las relaciones son verticales y en sentido único; lo que quiere decir que los intercambios dentro verticales no representan ni siquiera el $1 \%$ de sus intercambios dentro del Magreb también que la casi totalidad de los inters intercambios totales. Esto supone hace con los países del Norte. Lo intercambios de cada uno de estos países se

\section{RFS}


prescindir de los intercambios con el Norte, mientras que este puede perfectamente prescindir de su intercambios con el Magreb.

Si dejamos de lado el petróleo, los paises del Sur importan bienes que son estratégicos para ellos y exportan hacia ei Norte bienes que no lo son para éste.

En este marco es donde deben analizarse los intercambios de bienes de equipo, de bienes alimenticios, de bienes culturales, de armamento y, también, por supuesto, los mecanismos monetarios, los problemas de endeudamiento y los fenómenos migratorios. Dejando aparte el endeudamiento y las exportaciones de petróleo, los otros indicadores no remiten primeramente al espacio mundial; son fenómenos que conciernen sólo a la Comunidad Europea y a los tres paises del Magreb: Marruecos, Argelia y Túnez:

\section{Los problemas del endeudamiento}

Los problemas no tienen ni siquiera las mismas apariencias cuando se pasa de un país a otro del Magreb, dado que constituyen una pesada carga, y que condicionan desde hace una decena de años a las tres sociedades.

- Argelia es el país más endeudado: 27 mil millones de dólares en 1992, o sea $238 \%$ de sus exportaciones; por otrolado, el servicio de la deuda representa para Argelia el $71 \%$ de sus exportaciones. La deuda argelina es, en un $75 \%$, de origen privado, lo que quiere decir que ha sido contraida en el mercado financiero internacional, y que tiene tasas de interés elevadas, con plazos de vencimiento cortos, que además es negociable en el Club de Londres. El peso de la deuda argelina se alivió entre 1981 y 1985 , pero volvió a aumentar a partir de 1986 cuando los responsables argelinos se vieron obligados a compensar las caídas de los ingresos procedentes del petróleo con nuevos créditos que a su vez tenían plazos de vencimiento cada vez más cortos.

El gobierno de A. Ghozali era favorable a una renegociación de la deuda argelina. Estaba a punto de negociarlo cuando fue asesinado Mohammed Boudiaf. A. Belaid rechazó este tipo de programas y ha elegido-zpor cuánto tiempo?-volver a algunas de las soluciones que él mismo había aplicado cuando fue ministro bajo la presidencia de Boumedian.

- Marruecos con 21 mil millones de dólares de deuda -lo que representa $299 \%$ de sus exportaciones- es el país donde la deuda ha generado unos programas de ajuste estructural masivos cuando, a partir de 1983, no pudo afrontar sus

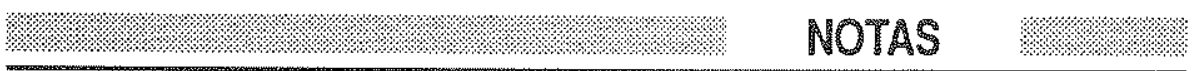


compromisos y debió pedir y negociar la refinanciación de su deuda. Por ello y 1992 . También podiarse de cinco aplazamientos de los vencimientos entre 1985 al $34 \%$ de sus exportaciones, pero de su deuda exterior sólo representa del 30 reembolsos, beneficiarse de nuevas ello ha permitido, además de retrasar los money", como dice el Plan Brady) aportaciones en "dinero caliente" ("hot países más endeudados del mundy). Marruecos se encuentra entre los siete activos exteriores en divisas y en, no en valor absoluto sino en relación a sus economía. Sólo el $17 \%$ de la en relación a la capacidad de exportación de su

forman parte del Club de Londres.
Al cabo de diez años de han permitido de alguna funcionamiento, los Programas de ajuste estructural res, así como también mostran corregir los desequilibrios financieros exteriosector público y de una administrar graves despilfarros y las desviaciones de un planes han mostrado que la economión sin ningún control real. También dichos resistencia frente a las variaciones co marroquí es muy frágil, vulnerable y sin exterior. El liberalismo, si no estáticas y a los choques procedentes del comportamientos sociales, va a está bien controlado y bien anclado en los social, el poder y los medios de utilionar en provecho de los que tienen el status cada vez más. Por ello, el éxito de utilizarlos. Esto es lo que ocurre en Marruecos llegar sino a condición de que los Programas de ajuste estructural no puede contemplados y favorecidos, que las graves sociales sean de alguna manera se ponga freno a esta socieda a las graves desigualdades sean atenuadas y que estructurado, ¿tiene acaso el poder docidades. El Estado, único actor que está

- Túnez con 12 mil millo poder de hacerlo? ¿desea siquiera hacerlo?

con el Fondo Monetario Interno dólares de deuda, ha entrado en negociaciones deuda tunecina representa el $25 \%$ de y el Banco Mundial. El servicio de la fico. A pesar de las dificultades dus exportaciones, lo que no es catastrógenerados por el endeudamiento de financiación, los ajustes financieros ligeros y han podido ser asimilado resultado, después de todo, bastante

\section{La cooperación con la Comunidad Europea}

El 67\% de los intercambios de los tres países del Magreb se realizan con

la Comunidad Europea, mientras que estos intercambios no representan sino 
el $2 \%$ de los intercambios globales de los países de la Comunidad.

El peso de España y de ltalia crece rápidamente. España se ha transformado en el segundo cliente y en el segundo proveedor de Marruecos, ocupando Italia el cuarto lugar en ambos casos.

Las relaciones entre Marruecos y la CEE, tanto en sus aspectos comercial y financiero como en los temas de la mano de obra y del medio ambiente, son muy dependientes y tributarios del marco institucional de los acuerdos de cooperación de 1976. Pero tanto la Política Mediterránea Renovada (PMR) como el nuevo marco de cooperación propuesto bajo la presidencia española y portuguesa son también instrumentos que merecen más atención y mucho interés.

\subsection{La Politica Mediterránea Renovada (la PMR)}

Esta política está condicionada por el proceso de cambios políticos profundos que ha conocido Europa del Este. El muro de Berlín cae en 1989, por supuesto, pero también se produce la apertura de la Comunidad Europea hacia la Europa Central:

- En julio de 1989, la Comunidad firma el programa "Polonia-Hungria, Ayuda a la Restauración Económica" (PHARE).

- En 1989-1991, se pone en marcha el Banco Europeo de Reconstrucción y Desarrollo (BERD) encargado de contribuir a la reconstrucción de las economías de Europa Central.

- El 16 de Diciembre de 1991, la Comunidad firma acuerdos de cooperación con Polonia, Hungria y Checoslovaquia, para crear a corto plazo una zona de libre cambio que debería conducir en un plazo de tres años a la adhesión de estos países a la Comunidad Europea.

En relación a los países mediterráneos en general, y a los tres países del Magreb en particular, la PMR comporta tres aspectos esenciales:

- en primer lugar unos protocolos financieros clásicos,

- a continuación, una cooperación financiera horizontal,

- y, por último, unas concesiones comerciales puntuales.

Los protocolos financieros contienen una parte programable y una parte no programable. 
La primera está financiada por donaciones del presupuesto comunitario hasta un $38 \%$ y por préstamos del Banco Europeo de Inversiones a razón del $62 \%$ en un plazo de 20 años y al $1 \%$ de interés.

La segunda parte tiene como objetivo animar las reformas estructurales mediante un apoyo a los sectores sociales, a la formación y a la creación de empleos. A través de este eje, la Comunidad aporta su sostén a los programas de ajuste estructural de Marruecos.

Argelia y Túnez se habrían beneficiado a partir de enero de 1992 de la firma del cuarto protocolo financiero por el Parlamento europeo, pero este protocolo ha sido rechazado para Marruecos por "su falta de respeto a los derechos humanos"; este cuarto protocolo relativo a Marruecos acaba de ser firmado en octubre de 1992 en Estrasburgo.

La cantidad de cuatrocientos sesenta y tres millones de Ecus que propone este cuarto protocolo se reparte de la manera siguiente:

220 millones de ecus de préstamo del $\mathrm{BEI}$,

218 millones de ecus en forma de donaciones,

25 millones de ecus en ayuda a la formación de capital riesgo en el marco de la llamada "cláusula Cheysson".

El acuerdo sobre la pesca que ha sido firmado entre Marruecos y los países de la CEE en 1987 llegó a su fin en 1992, y ha sido suspendido como consecuencia del rechazo del Parlamento europeo a firmar el cuarto protocolo financiero. Un nuevo acuerdo ha sido concluido en la fase negociadora del acuerdo general sobre el estatuto global de colaboración.

La PMR de la Comunidad se ha planteado en un contexto en el que los problemas del endeudamiento se han transformado en unos cuellos de botella o estrangulamientos para los países del sur del Mediterráneo. Por ello, el debate sobre la creación de una institución de financiación para estos países tiene repercusiones más políticas y polémicas que financieras. ¿Habría que crear un Fondo Europeo de Ayuda al Desarrollo, como propone Francia? ¿O más bien crear un Banco Mediterráneo de Reconstrucción y de Desarrollo (BMRD) para los países mediterráneos semejante al BERD, como lo proponían España e
Italia? 


\subsection{La cooperación en el ámbito del medio ambiente}

Las preocupaciones ligadas al entorno formarán parte en adelante de los puntos claves de la cooperación, y por ello los protocolos financieros y los acuerdos de tipo general integran cada vez más esta exigencia, principalmente desde enero de 1990 y desde el grito de alarma lanzado en Río de Janeiro en 1992 sobre la urgencia de una cultura del medio ambiente.

La PMR mantiene varios capitulos en este sentido; para ello se propone la concesión de una serie de líneas de crédito por parte de la C.E.E. para los siguientes fines:

- la protección y el desarrollo de las zonas costeras;

- el desarrollo de las zonas urbanas de crecimiento rápido;

- la protección de la naturaleza y de los entornos frágiles;

- la gestión đe los residuos, y la lucha contra la desertificación.

Se constata en estos capítulos que la Comunidad está decidida a alentar un conjunto de preocupaciones mundiales en relación con los males que resultan de la internacionalización de los circuitos de droga, con los peligros de la contaminación y con la toma de conciencia de la interdependencia de los espacios a nivel mundial.

El auge del integrismo y los movimientos migratorios clandestinos han impuesto dos nuevos ámbitos en las relaciones entre el Magreb y la C.E.E.: la cooperación cultural y el control del crecimiento demográfico por los países de Europa, así como el respeto de los derechos humanos.

\section{A modo de conclusión}

Desde la entrada en vigor de la convención de Schengen el 19 de junio de 1990 sobre la armonización de las políticas de acceso a Europa para los residentes del Tercer Mundo, los problemas y los conflictos se han acentuado y agravado debido a los choques provocados por la guerra del Golfo, a los problemas de Argelia, y a los "boat-peoples" en el estrecho de Gibraltar. ${ }_{\measuredangle} \mathrm{Cabe}$ decir que el Mediteráneo se ha convertido en una "nueva frontera"?

Una serie de perspectivas nuevas se abren y deben ser dinamizadas en interés de los pueblos. $Y$ esto puede hacerse sea en términos de proyectos en común, de inversiones europeas en el Magreb sea, sobre todo, en el marco de una 
cooperación sobre unas nuevas bases distintas de aquellas que estaban ligadas a las ventajas de una mano de obra abundante y barata. Así, la C.E.E., bajo la presidencia de España y después de Portugal, ha propuesto a Marruecos y luego a Túnez un nuevo marco de colaboración y de cooperación que integra la cooperación financiera, tecnológica, cultural y la constitución de una zona de libre cambio en un marco de co-desarrollo. Es decir, un "juego de suma positiva", como dice Jacques Delors.

En este sentido es un paso importante hacia la creación de una salida posible para las relaciones entre el Norte y el Sur del Mediterráneo: la constitución de un Espacio Mediterráneo Global. 